Recibido: 15 octubre 2019 | Aceptado: 30 octubre 2019 | Publicado: 1 diciembre 2019

Cita: Puertas, E. (2019). Reseña sobre La fraseología del desacuerdo. Los esquemas fraseológicos en español, de Mura, G. Angela. Sevilla, Editorial Universidad de Sevilla, 2019, 140 páginas. ISBN: 978-84-472-2856-0. Normas, 9, 242-244. doi: https://doi.org/10.7203/Normas.v9i1.16059

\title{
Reseña sobre La fraseología del desacuerdo. Los esquemas fraseológicos en español, de Mura, G. Angela. Sevilla, Editorial Universidad de Sevilla, 2019, 140 páginas. ISBN: 978-84-472-2856-0
}

Elia Puertas Ribes

Universitat Jaume I 
El campo de la fraseología abarca un gran número de unidades fraseológicas (en adelante, UF), organizadas por medio de un complejo continuum que comprende desde las categorías 'núcleo', cuyas propiedades esenciales son la fijación y la idiomaticidad, hasta aquellas estructuras situadas en la 'periferia', debido a la carencia de las características prototípicas de las UFs. La obra reseñada examina los esquemas fraseológicos mediante un análisis formal y funcional de sus unidades con el objetivo de otorgarles un espacio propio dentro del discurso repetido. El trabajo que aquí nos ocupa se constituye como una gran aportación tanto para el estudio de la lengua hablada, como para la disciplina de la fraseología, dado que propone una definición teórica que pretende sistematizar estos esquemas en el ámbito fraseológico del español.

El primer capítulo introduce el objeto de estudio, tres estructuras pluriverbales que sirven en el discurso para mostrar desacuerdo: qué $+X+$ ni qué $+X$ ( Qué hombre ni qué niño muerto!); qué + verbo ir + a + X (¡Qué voy a pensar!); será por + X (¿Será por sillas?). Para ello, G. Angela Mura reúne un total de 34 esquemas fraseológicos extraídos de las siguientes bases de datos textuales del español hablado: Corpus de conversaciones coloquiales Val.Es. Co (Valencia, Español Coloquial), Corpus Oral de la Variedad Juvenil Universitaria del Español Hablado en Alicante COVJA, de Dolores Azorín Fernández y Juan Luis Jiménez Ruiz; COLA (Corpus Oral de Lenguaje Adolescente) de la Universidad de Bergen; el CREA (Corpus de Referencia del Español Actual) de la Real Academia Española; y el corpus multilingüe C-ORAL-ROM (Integrated Reference Corpora for Spoken Romance Languages).

En el apartado segundo, la autora recopila las referencias bibliográficas más relevantes de los estudios realizados hasta el momento acerca de las estructuras fraseológicas. Mura parte de la distinción entre los autores que estudiaron las UFs desde un acercamiento estrictamente fraseológico y los que, por el contrario, llegaron a ellas por otros caminos. Este capítulo es de lectura imprescindible para situarse en el tema que nos concierne y llegar a comprender la definición que propone al adoptar la etiqueta terminológica de esquema fraseológico.

El capítulo siguiente enlaza con el anterior, ya que aporta una visión teórica sobre sus características formales y funcionales. En líneas generales, describe seis de los valores que adquieren estas unidades en el discurso: el desacuerdo muestra la discrepancia con lo dicho por el interlocutor, regulado por una escala gradual. Sucede de forma similar con la réplica, vinculado con la idea de rechazar con mayor agresividad lo expuesto anteriormente. La construcción-eco y la repetición son dos fenómenos que están fuertemente unidos $\mathrm{y}$, como destaca la autora, permiten situar los esquemas fraseológicos «entre la sorpresa, la ironía, el desacuerdo parcial y el desacuerdo total». La polifonía enunciativa alude a la aparición de dos interlocutores diferentes en un mismo enunciado, es decir, un hablante emite una enunciación que otro participante repite con el objetivo de mostrar su rechazo y alejarse de las palabras emitidas. En este sentido, consigue trabajar la polifonía de los esquemas fraseológicos como una forma particular del discurso repetido. Por último, detalla la negación, cuya función principal es la de enfatizar o reforzar la réplica a lo dicho anteriormente por otro interlocutor. La lectura de este capítulo ofrece al lector una óptica detallada sobre los valores discursivos más destacados de estas unidades. 
G. Angela Mura, en el cuarto apartado, presenta el análisis de tres esquemas fraseológicos según los rasgos inherentes a su estructura formal y el papel que desempeñan en el discurso. Este capítulo es el más extenso, ya que expone una gran variedad de ejemplos reales que ilustran de forma práctica los rasgos de estas unidades. Con ello, demuestra la estrecha relación entre la estructura y los valores gramaticales con las funciones pragmáticas.

El primer esquema es iqué $+\mathrm{X}+$ ni qué $+\mathrm{X}$ ! (iqué hombre ni qué niño muerto!) compuesto por dos elementos libres y dos fijos. La casilla vacía libre es sustituida por la palabra del enunciado anterior que se quiere negar; en cambio, la segunda parte disponible es una sección 'semi-libre', pues las posibilidades para elegir están restringidas a un inventario de posibilidades cerrado. En ambas casillas, los hablantes pueden emplear tanto fórmulas despectivas, como palabras malsonantes o, incluso, términos más decorosos, como los eufemismos. Gracias al corpus oral, observa que, en ocasiones, los esquemas fraseológicos no se completan, y quedan en una construcción suspendida por no encontrar la palabra adecuada.

El esquema fraseológico qué + verbo ir + a + X (iqué voy a pensar!), a nivel formal, está compuesto por una parte fija, que posee el valor de negación, y una parte libre que se adapta según el contexto de cada situación comunicativa. A nivel funcional, se trata de una interrogación retórica que repite el elemento sobre el que se quiere expresar desacuerdo, rechazo, descrédito o incredulidad dentro de una secuencia dialogada, puesto que no se niegan las propias palabras, sino las de otro hablante. Además, Mura permite comprender mejor esta estructura gracias al acercamiento sociolingüístico que ofrece a través de los ejemplos recogidos.

La última construcción, ¿será por + X? (¿será por sillas?), también está compuesta por dos partes: la primera es inalterable y está encabezada por el verbo ser en futuro de indicativo en $3^{a}$ persona singular, y seguido por la preposición por; la segunda, se compone por una casilla variable según el contexto discursivo. En cuanto a su comportamiento en el discurso, se trata de una expresión interrogativa que se emplea en sentido irónico y produce interferencias negativas.

En las consideraciones finales, tras haber expuesto la investigación realizada, la autora aporta una definición teórica acerca del concepto de esquema fraseológico. El libro concluye, por tanto, con una revisión de la forma y la función de tres esquemas, así como una pequeña reflexión sobre la fijación -característica esencial en las unidades fraseológicas-, que se aprecia de forma parcial en estos esquemas, dado que es la variación uno de los rasgos esenciales que les permite adaptarse al escenario comunicativo en el que se emplean. Consigue dar cuenta de los distintos valores pragmáticos que puede albergar la unidad con el fin de mostrar desacuerdo entre dos o más interlocutores y la vinculación semántica con el contexto anterior. Por todo ello, la lectura de la obra reseñada, además de ser clave para profundizar en el estudio de una de las categorías 'periféricas' más fluctuantes de la fraseología, resulta interesante para los estudiosos del discurso oral, y también para toda la comunidad lingüística que quiera conocer más sobre la relación entre el discurso repetido y la sintaxis libre. 